\title{
Editorial
}

\section{Can we still afford Antarctic science?}

$\mathrm{B}$ ig science is expensive. Not just astronomy, high-energy physics, and space research but Antarctic science as well. How then will it fare in the present global crisis? The current financial problems have elicited different approaches to science spending. President Obama decided that investing in science was part of his strategy for the future and thus science funding to NSF has increased. In Germany science funding through the Helmholtz Association seems unchanged. In Britain the coalition government has decided that the only way to fix the debt problem caused by the banks is to squeeze the government spending hard and share the pain around. The Research Councils have seen significant reductions in their income.

Establishing and maintaining infrastructure on the continent, as well as providing the transport and work platforms, is expensive and thus an easy target when savings need to be made. This was the position thirty years ago when British Antarctic Survey was told to reduce staff and stations to help meet the then shortfall in the Natural Environment Research Council (NERC). The cycle now comes round again with a sustained attempt by NERC since early 2011 to severely reduce BAS funding in order to protect the grants it gives to universities, effectively neutering BAS science. The argument about this rose through the Civil Service all the way to the National Security Council, according to a recent article in the newspaper The Independent on Sunday. The article maintains that this not only precipitated a decision by the Prime Minister and the Foreign Secretary to declare that Britain needed to maintain the existing level of activity (but forgot to provide any extra funds to underpin this) but also fuelled a dispute in which the Director of BAS, Professor Nick Owens, was forced to step down for attempting to protect BAS science in the national interest. In response NERC quickly announced that $£ 42$ million a year would be provided through until 2015 and that this was a generous settlement under the circumstances. Sadly, they forgot to mention that this would not allow for inflation and that they would be withdrawing their agreement to cap the payments for fuel the two BAS ships. So the funding will effectively decline at a rate of at least $5 \%$ a year, more rapidly if oil prices continue to rise.

Despite Britain's undoubted leadership in many aspects of Antarctic science, despite the importance for the British Government of the political presence provided by BAS, and despite the importance of Antarctic data in modelling our future under climate change, the failure of the Government to adequately manage science and recognise its long-term strategic importance is clearly demonstrated by the present situation. Science and the universities are currently funded through the Department of Business, Innovation and Skills headed by an economist, a decision possible only by politicians who are lawyers and economists and see science as a potential cash cow rather than in its widest role. They certainly do not understand Antarctic political presence or science as a cultural asset.

The future of BAS is clearly under threat and this may also be true in these difficult times for other Antarctic and science bodies. All nations active in Antarctica are there because of a political commitment as well as scientific interest, which need to be managed and delivered jointly to be effective. Surely this is especially true for the claimant nations? One can only hope that the two taken together will continue to drive a long-term commitment to work in Antarctica for the benefit of everyone. At present the future is not bright.

DAVID WaLton 